\title{
ANÁLISE DA PRODUÇÃO DO PINTOR ANÍBAL MATOS EM BELO HORIZONTE - 1917-1944
}

Rodrigo Vivas Andrade

Doutorando em História da Arte - Unicamp

Bolsista do CNPQ

O objetivo desse texto é apresentar a trajetória do pintor Aníbal Matos no período de 1917-1944. O início de meu estudo coincide com a vinda de Matos para Belo Horizonte e se encerra com a perda da hegemonia desse pintor após os acontecimentos artísticos e políticos de 1944: construção do complexo da Pampulha, suspensão dos Salões de Arte da Prefeitura de Belo Horizonte (SAP) e a inauguração da Exposição Moderna de 1944. No que se referem especificamente as suas pinturas foram analisadas neste texto: Paisagem com carro de bois (Figura 1); Jardineiro (Figura 2); Chafariz. (Figura 3), Casas Antigas (Figura 4).

Aníbal Matos nasceu no Arraial do Comércio, em Vassouras, no Estado do Rio de Janeiro aos 26 de outubro de 1886 e faleceu em Belo Horizonte em junho de 1969. Ficou conhecido como pintor, escritor, historiador da arte e professor. Fez seus estudos primários em Icaraí, Niterói, e freqüentou o curso secundário no Mosteiro de São Bento e no Colégio D. Pedro II. Sua família era ligada às artes plásticas, dois de seus cinco irmãos tornaram-se artistas: Antonio (escultor) e Adalberto (pintor e gravurista).

Casou-se com D. Maria Ester, com quem teve oito filhos dentre os quais o pintor modernista Haroldo Matos $^{1}$ e a pintora decorativa Maria Ester Matos. Seus dois filhos participaram, conjuntamente com o pai e a mãe, de várias exposições realizadas em Belo Horizonte. Aníbal Matos foi ainda, fundador de várias sociedades culturais no Rio de Janeiro como o Centro Artístico Juventas, depois transformado em Sociedade Brasileira de Belas Artes, da qual foi benemérito.

1 Nasceu em Belo Horizonte, 1926. Desenhista, pintor, fotógrafo e professor. Foi diretor da EBA/UFMG, BH (1966-68), e fundador do I Festival de Inverno da UFMG, nos anos 1960. Filho de Aníbal Mattos, freqüentou a Escola de Belas Artes de BH sob orientação de seu pai. Na década de 1940 estudou com Guignard na sua escola e, em 1951, na Escola do Louvre, em Paris. Faleceu no dia 11 de setembro de 2005 em Belo Horizonte. 
Aníbal Matos fez seus primeiros estudos de desenho no Liceu de Artes e Ofícios do Rio de Janeiro e, posteriormente, estudou na Escola Nacional de Belas Artes na mesma cidade, e foi aluno de João Batista de Costa, Daniel Berard e João Zeferino da Costa. Em 1910, aos 24 anos de idade, recebeu o prêmio de viagem ao estrangeiro no Salão Nacional do Rio de Janeiro, deixando-o para outro pintor,como informa ÁVILA (1991, p. 8), "porque nesta época conheci uma mineirinha de Sabará, minha melhor aluna de arte". Matos casa-se com a referida aluna desistindo do prêmio de viagem obtido em $1910 \mathrm{com}$ Judas o traidor:

de tema e composição acadêmicos, onde as pinceladas finas, a superfície lisa e o desenho de contorno bem definido denotam as características do ensino artístico da época. (AVILA, 1991, p.8).

$\mathrm{Na}$ trajetória de Matos, o período que mais interessa à abordagem deste texto, tem seu início no ano de 1917, momento em que se transfere para Belo Horizonte a convite de Bias Fortes para ocupar o cargo de professor da Escola Modelo e como já foi mencionado se encerra em 1944 com o conjunto de medidas de Juscelino Kubitschek como prefeito de Belo Horizonte. A cidade já conhecia as pinturas de Aníbal desde 1913, data das primeiras exposições realizadas nessa cidade como comprovado nas matérias do jornal Diário de Minas.

Além de professor da Escola Modelo, trabalhou na Escola Prática de Belas Artes. Em 1918, funda a Sociedade Mineira de Belas Artes onde se realizam as exposições de arte na capital mineira. Essa sociedade patrocinou a Primeira Exposição de Arte Moderna: a exposição de Zina Aita. No que se refere à arte acadêmica, Aníbal realizou seguidamente durante 15 anos, 15 Exposiçôes Gerais de Belas Artes sem o auxílio do governo. ${ }^{2}$

Paisagem com carro de bois (Figura 1), foi a obra mais antiga de Matos que encontrei e que corresponde as propostas estéticas apresentadas nas suas primeiras exposições em Belo Horizonte. Essa obra pintada em 1916 retrata um tema que o tornará conhecido para os mineiros: as paisagens de Minas Gerais. Essas paisagens, assim como outras características estereotipadas, farão parte do acervo de imagens que distinguirá o universo da mineiridade.

2 Ainda não foram produzidos estudos sobre as Exposições Gerais de Belas Artes que tinham a coordenação do pintor Aníbal Matos no início do século XX em Belo Horizonte. 
Os pintores acadêmicos não se interessaram pela criação de imagens modernas, ficaram presos justamente ao que estava por desaparecer na capital mineira: o trabalhador do campo, as casas de fazenda antiga, o isolamento proporcionado pelas montanhas e a relação com a cidade de Ouro Preto. Esses pintores olhavam para Belo Horizonte, mas conseguiam apenas ver o que poderia restar do Curral Del Rei. Gesto que se aproximava de Charles Baudelaire quando andava pela cidade de Paris e, como nos demonstra no Pintor da Vida Moderna, ${ }^{3}$ com a curiosidade pela efemeridade dos eventos que estão prestes a se diluir com a velocidade da modernidade.

Tais imagens foram escolhidas pelos colunistas como as mais apropriadas para representar a paisagem mineira, mas como se sabe ela corresponderam muito mais a um conjunto de arquétipos ligados ao imaginário rural existente no Brasil do que a uma característica específica das paisagens mineiras. Todavia, é importante perceber como a crítica e os pintores da época buscavam construir uma relação identitária e de pertencimento ao enxergarem nessas imagens a materialização da essência mineira.

Um carro de bois conduzido por um trabalhador descalço em uma estrada de terra cercada por montanhas. Minas, como diria Guimarães Rosa, é em primeiro lugar uma montanha. As montanhas de Minas Gerais, responsáveis por diferenciar a personalidade dos mineiros, recebem destaque em inúmeras cenas pintadas no período.

Nota-se entretanto que os pintores da cidade de Belo Horizonte na primeira metade do século XX estavam dialogando com uma série de imagens construídas ao longo dos séculos, começando por viajantes como Saint-Hilaire ou por historiadores como Gilberto Freyre, o primeiro a utilizar o termo "mineiridade". Segundo Pinheiro Chagas, o mineiro estaria entre o trabalhador rural qualificado pelo bom senso, pela estabilidade e pelo conservadorismo e o minerador aventureiro e amante da liberdade. Como informa HOLANDA (1978), essas tipologias podem ser encontradas não apenas em Minas Gerais, mas no Brasil. O interessante é atentar-se pelo choque de representações e como as imagens são apropriadas em novos contextos para construção de novos imaginários.

3 BAUDELAIRE, Charles. O pintor da vida moderna. In: (Textos inéditos selecionados por Teixeira Coelho) A modernidade de Baudelaire. Rio de Janeiro: Paz e Terra, 1988. 
É necessário notar que o isolamento produzido pelas montanhas teria forjado uma personalidade discreta, desconfiada e a cruz no final da estrada representada na pintura de Matos parece incorporada ao espaço monumental. $\mathrm{O}$ mesmo tipo de imagem de trabalhadores em uma região isolada também é representada em outro quadro de Aníbal Matos em 1915. O Jardineiro (Figura 2) exibe um trabalhador segurando uma enxada com a mão direita e com o seu braço esquerdo apóia-se na perna, sentado em um banco. Entre as árvores existe um caminho que leva a uma pequena casa ao fundo separando o primeiro plano (o trabalhador) e o segundo plano (a casa).

A construção do tempo tem um papel fundamental nessas duas imagens. Um tipo específico de tempo, das estruturas, para utilizar uma definição do historiador francês Fernand Braudel (1978). Os valores estáveis desse homem do campo se confundem com a temporalidade das montanhas mineiras. O tempo da estabilidade, do conservadorismo, dos temas que reafirmam os estereótipos da mineiridade. As imagens fugazes da modernidade apresentam-se como "vagalumes na noite brasileira: eles brilham, mas não iluminam o caminho", como afirmou Braudel em declaração quando seu carro se quebrou em uma estrada da Bahia.

Apesar de as críticas publicadas nos jornais belohorizontinos do período apontarem uma especificidade das representações de Aníbal Matos para as paisagens mineiras, esta idéia parece não ser sustentável ao se compará-lo com outros pintores acadêmicos como Almeida Júnior, Antônio Parreiras, Georg Grimm.

\section{Exposições Públicas e Exposição Geral de Belas Artes}

Em sua atuação em terras mineiras, Matos tenta transferir o modelo artístico da Escola Nacional de Belas Artes para Belo Horizonte, o que exige a apresentação de algumas referências históricas sobre o reduto do academicismo no Brasil.

Aníbal Matos consegue, nesta primeira exposição, congregar um conjunto de artistas acadêmicos que eram referências obrigatórias nas artes do Brasil dos quais podemos citar ${ }^{4}$ : Amaedo (Rodolfo Amoedo), Agrette (Francisco Agrette), A. Duarte, A. Mattoso, A. Faro, A. Selva, A. Cunha, A.

4 Foi difícil reconhecer alguns nomes devido à escrita e às abreviações. Entre parênteses constam algumas hipóteses de nomes que não foram reconhecíveis de imediato. 
Novacq, A. Ford, Arthur Thimotheo (Artur da Costa Timótheo), B. Parlagreco (Salvador Parlagreco), Brocos, (Modesto Brocos Y Gómez) B. Facheti, Celso Wernecq, Childe, Caron, Carlos Oswaldo, Castagnette, Domenicq, Eduardo de Martino, E. Fabrege, E. Engelhardt, Estevam Silva, E. Simonetti, Esther de Mattos, Steckel, Fernandino Júnior, Francisco Rocha, Pons Arnau, F. Forimelli, Grimm, Goldchimidt, Z. Cantagalli, J. Quintino, I. Gonzoles, José M. Pacheco, L. Ferry, A. Belém, Oscar Pereira, Petrina Coutinho, H. Cavalheiro, Honório Esteves, Nadir Meirelles, P. Fantine, Souza Pinto, Scweigofern, Helena Agretti, José Jacinto das Neves e Antonio Carneiro (retratista português). (Diário de Minas. 27/09/1917).

Ainda no ano de 1917, Belo Horizonte, recebeu de Aníbal Matos a Escola Prática de Belas Artes que segundo consta no Minas Gerais: "Inaugurar-se-á, a 7 do corrente, no palacete Celso Werneck essa escola, (escola prática de Belas Artes), sob a direção do laureado artista professor Aníbal Matos. (Minas Gerais. 06/08/1917). Segundo a matéria, seria desnecessário enaltecer "a brilhante iniciativa que vem implantar em Minas Gerais o ensino de Belas Artes, sob os processos das escolas superiores dessas matérias". (Minas Gerais. 06/08/1917) Como programa inicial da Escola, destacaram-se dois princípios essenciais para o ensino da arte acadêmica: desenho e pintura.

Após a Exposição Geral de Belas Artes Aníbal continua sua produção recebendo constante atenção da crítica de arte da capital ${ }^{5}$. No ano de 1923, expõe em Belo Horizonte 150 quadros e passa neste momento, a ser reconhecido por algumas obras.

O artista consagrado da "Cruz dos Caminhos" e consciencioso interprete de nossa paisagem não tem dormido sob os louros conquistados com as suas obras, muitas das quais provaram a admiração de uma realeza - o soberano da Bélgica, que teve palavras de elogio para o pintor quando aqui esteve há três anos. Aníbal, de então para cá, tem trabalhado com coragem e não é raro encontrá-lo pelos arredores da cidade com cavalete e demais apetrechos de ofício, a transportar para a tela, com aquele vigor de técnica e justeza (...)" (Diário de Minas. 06/09/1923)

Ler algumas críticas é ser convidado a visitar as exposições de Aníbal Matos. Andar por todos os espaços, entender a distribuição das telas na exposição e como informa a matéria do Diário de Minas seria como encontrar paisagens "cheias de sol e alegria". A obra Alterosa Plages seria suficiente, segundo o colunista, para recomendar a exposição de Aníbal

5 Os termos "colunista" e "crítica da arte da capital" se referem ao conjunto de artigos publicados nos jornais da capital mineira, mas que não eram assinados. 
Matos, pois as obras "falam da mesma forma à alma, provocando essas emoções que só a verdadeira arte tem o dom de nos transmitir". (Diário de Minas, 06/09/1923)

Todavia o quadro mais aclamado pela crítica foi Flores da Primavera, ainda segundo a crítica convida o expectador ao "deslumbramento que empolga o visitante ao penetrar no chofre". A exposição de Matos foi realizada no Conselho Deliberativo onde era possível conviver com dezenas de quadros que ocupavam a maior parte das paredes com

paisagens luminosas, onde o sol arde e esplende, vibra e ofusca, e que melhor se podem compreender o temperamento e os processos originais, a técnica, tão vigorosa e segura, do paisagista inconfundível da 'Cruz dos Caminhos"'. (Diário de Minas, 20/09/1923).

Matos seria capaz de materializar a luminosidade do sol em suas pinturas. Um pintor que por transformar a luz em obsessão produz

um hino glorificador da luz, uma ode ao sol fecundo e criador. Em volta de nós, a cada canto em toda parte o sol arde. A heliofilia desse "virtuose" do sol é uma característica fundamental de sua obra. "Primavera florida" como rigor da fatura de pinceladas largas, e de efeito seguríssimo é de uma perfeição absoluta. Observa-se nessas telas perfeita perspectiva aérea, circulação de ar e uma raríssima vibração de luz, que destaca todo o quadro, que parece iluminado pelo próprio sol, sem violência de claro escuro. O céu é profundamente brasileiro, de um azul transparente, com mássicos de nuvens, tão comuns nos nossos dias tropicais de intensa luz. É um quadro alegre, otimista, vibrante, com os seus tons radiantes de primavera em flor. Impecável na gravação de planos, ainda há de notar nessa obra prima a transparência das águas, em que se reflete a paisagem original. (Diário de Minas. 20/09/1923)

As exposições se transformaram em um espaço de socialização e os quadros eram adquiridos como um fator de distinção social. Geralmente ao final dos comentários das exposições, eram apresentados os importantes membros da sociedade mineira que adquiram obras como mostra a citação que se segue: "Sr. e Sra. Alcina Barbosa de Souza, Deputado Joaquim Salles, drs. Oswaldo de Araújo, Clemente Faria, Arduido Bolívar, Manoel de Oliveira, Horácio Guimarães." (Diário de Minas, 29/09/1923) estaria

Este fato pode ser confirmado por outra citação que atesta que

6 O quadro "Cruz dos caminhos" se transformou na referência da crítica de arte mineira para caracterizar Aníbal Matos como um pintor respeitado. Não foi possível encontrar tal obra que parece ter sido queimada no incêndio na Estação da Luz. 
definitivamente lançada e de maneira vitoriosa a idéia de ser adquirido pelas classes sociais de Belo Horizonte o lindo quadro. Flores da primavera que deverá ser oferecido ao ilustre presidente Dr. Raul Soares. (Diário de Minas, 29/09/1923)

Apesar dessas relações entre compra de obras e distinção social, não se deve acreditar que o viés político seja o caminho adequado para analisar a atuação de Aníbal Matos ou, pelo menos, não é a minha opção nesse texto.

No ano de 1924, Aníbal Matos pinta Chafariz (Figura 3), que pertence ao Colégio Estadual Pedro II, onde se percebe a cor verde em contraste com tons amarronzados anteriormente aplicados no quadro Paisagem com carro de bois (Figura 1). Um detalhe importante é a dificuldade de Aníbal Matos em representar a vegetação espessa. A observação atenta da obra original permite perceber ao lado da fonte uma grande concentração de tinta que acaba por escorrer na tela destoando do restante do quadro. Para um quadro que pelas leituras habituais que dele são feitas representa academicamente um tema, uma grande concentração de tinta e a falta de tratamento da superfície do suporte parecem inconcebíveis.

No tocante, especificamente à pintura Chafariz (Figura 3) nota-se que o mesmo está situado ao lado de uma enorme ladeira que levaria a um conjunto de casas ao final do caminho. A localização é estratégica para que as pessoas tomassem água antes de iniciar sua subida ou depois de completar a descida da ladeira. A densa vegetação localizada ao lado do chafariz tem o objetivo de completar a composição do quadro, sendo perceptíveis às diferenças da representação entre o desenho e a pintura.

Aníbal Matos encontra em Belo Horizonte o espaço favorável para a consolidação de sua carreira artística decidindo, no ano de 1924, fazer uma grande exposição na cidade de São Paulo com quadros que obtiveram sucesso de crítica na capital mineira.

dentro de breves dias seguirá para São Paulo onde vai realizar uma grande exposição, o consagrado pintor Aníbal Matos, quer antes de para ali partir dar aos inúmeros admiradores que conquistou o seu pincel vitorioso nesta capital, uma amostra dos trabalhos que vão figurar naquele certame". (Díario de Minas. 03/05/1924).

A exposição recebeu o título de Terra Mineira que apresentava um artista de

excepcional merecimento, com uma palheta opulenta, rica de tonalidades imprevistas, interpretando com requintes de estesia e assombrosa segurança e felicidade aspectos inéditos e curiosos da nossa estonteadora e empolgante natureza. Falar sobre uma exposição de Aníbal Matos é tarefa fácil. Basta 
anunciá-la. As exposições do mestre admirável da "Cruz dos caminhos" e de "Terra Mineira", constituem sempre um acontecimento notável de que se fala por muito tempo. (Diário de Minas. 18/05/1924)

Os quadros de Aníbal Matos não foram expostos, foram queimados na Estação da Luz como conseqüência de uma sucessão de medidas autoritárias para o fim das oposições ao presidente Arthur Bernardes. O conjunto de fatos ficou conhecido no período como o reinício do movimento tenentista. As articulações entre civis e militares, iniciadas em 1923, direcionaram-se para a capital paulista sob o comando do general Isidoro Dias Lopes. A Estação da Luz não escapou ilesa. Foi queimada e toda a obra de Matos ali armazenada teve o mesmo fim. Apenas duas telas foram salvas: Mata iluminada e Terra Mineira, "únicas das suas telas que escaparam, milagrosamente, ao saque e às depredações dos mashorqueiros de São Paulo". (Diário de Minas. 06/12/1924).

Após a destruição de suas obras, o pintor realizou uma exposição em Belo Horizonte, mas passando a receber críticas negativas sobre seu trabalho. Não é possível saber se esse fato se deveu à pressa em recuperar sua produção ou uma mudança do perfil da crítica belohorizontina. Aníbal Matos foi comparado a Parreiras, que seria segundo a crítica do Diário de Minas, um paisagista de "delicada sensibilidade, de audácia de colorido", entretanto, ainda segundo a crítica, faltava em Matos "firmeza de técnica e não sabemos que mais". Essa característica, segundo o autor da coluna, seria infundada e elaborada por "quem está obrigado a fazer jornalismo apressado".

A obra de Aníbal Matos não pareceu sofrer grandes modificações, mesmo com as críticas à sua forma acadêmica de pintar e as comparações feitas à obra de Tarsila do Amaral e de Di Cavalcanti. Na obra Casas Antigas (Figura 4), de 1926, Aníbal pinta os mesmos temas históricos e não modifica a representação, sendo possível notar que o desenho ocupa uma parte muito reduzida do quadro, ficando ainda patente a dificuldade desse pintor na composição das cores. Matos busca, na mistura destas, produzir a sensação de movimento, porém o resultado do quadro é artificial e, para compensar sua limitação, utiliza o recurso de representação de uma estrada. 


\section{Imagens}

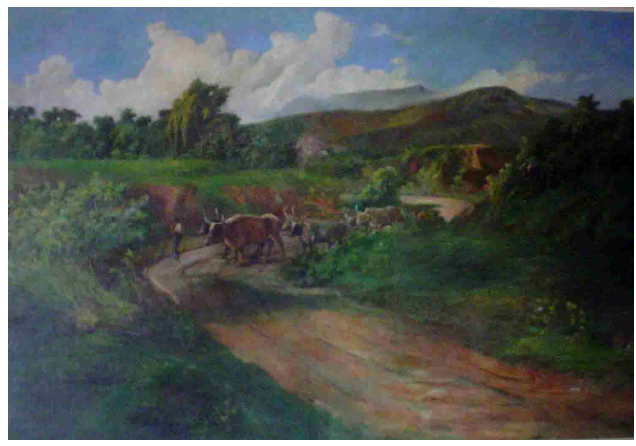

Figura 1: Aníbal Matos. Paisagem com carro de bois. Centro de Referência do Professor - Praça da Liberdade. Belo Horizonte. Minas Gerais

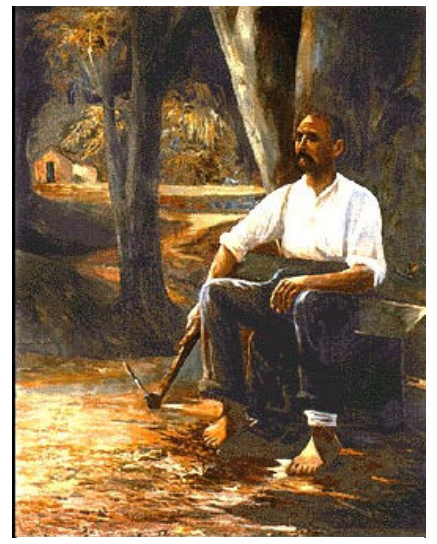

Figura 2: Aníbal Matos.

Jardineiro. Óleo sobre tela, 1915
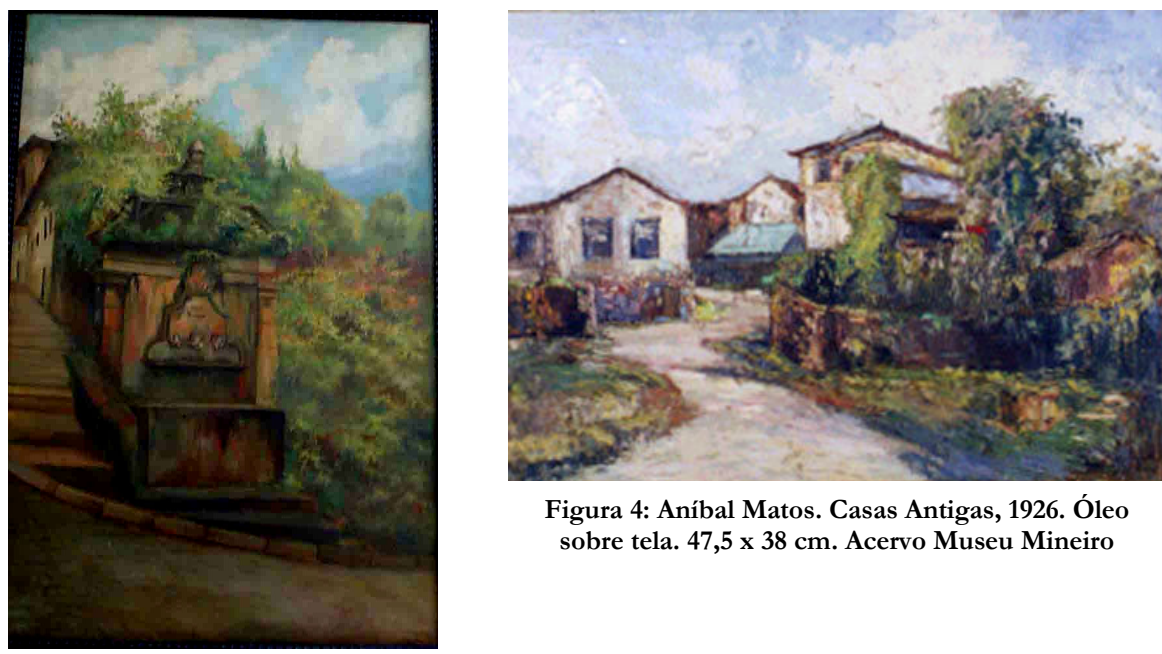

Figura 4: Aníbal Matos. Casas Antigas, 1926. Óleo sobre tela. 47,5 x $38 \mathrm{~cm}$. Acervo Museu Mineiro

Figura 3: Aníbal Matos.

Chafariz. Ouro Preto, 1924. Óleo sobre tela. $1,97 \times 1,35 \mathrm{~cm}$. Acervo

Escola Estadual Pedro II 


\section{Bibliografia}

AVILA, Cristina. Aníbal Mattos e seu tempo. Belo Horizonte, 1991.

OLIVEIRA, Myriam Andrade Ribeiro. Situação das Artes Plásticas em Minas no século XIX. In: Seminário sobre a cultura mineira no século XIX. Belo Horizonte: Conselho Estadual de Cultura MINAS GERAIS, 1982.

RIBEIRO, Marília Andrés. Um século de história das artes plásticas em Belo Horizonte Belo Horizonte: C/Arte e Fundação João Pinheiro, 1997. 